\title{
Synthetic Characterization of Complexes of Rosuvastatin and Some ACE Inhibitors: Pharmacological Evaluation
}

\section{Tabassum $\mathbf{A}^{1^{*}}$, Arayne $\mathbf{M S}^{1}$, Sultana $\mathbf{N}^{2}$ and Mehjabeen ${ }^{3}$}

${ }^{1}$ Department of Chemistry, University of Karachi, Karachi - 75270, Pakistan

${ }^{2}$ Research Institute of Pharmaceutical Sciences, Faculty of Pharmacy, University of Karachi, Karachi -75270, Pakistan

${ }^{3}$ Department of Pharmacology, Faculty of Pharmacy, Federal Urdu University of Arts, Science \& Technology, Karachi-75300, Pakistan

"Corresponding author: Tabassum A, Department of Chemistry, University of Karachi, Karachi - 75270, Pakistan, E-mail: arman_tabassum@hotmail.com

Received date: Feb 02, 2016; Accepted date: Jun 18, 2016; Published date: Jun 23, 2016

Copyright: @ 2016 Tabassum A, et al. This is an open-access article distributed under the terms of the Creative Commons Attribution License, which permits unrestricted use, distribution, and reproduction in any medium, provided the original author and source are credited.

\begin{abstract}
Rosuvastatin is an anti-hypercholesterolemic agent with good anti-inflammatory and antinociceptive responses. The objective of present study was to assess the pharmacological effects of interaction of rosuvastatin with coprescribed ACE inhibitors. For this purpose complexes of Rosuvastatin with enalapril, captopril and lisinopril were synthesized and characterized. Their spectroscopic analyses suggest that hydrogen bonded complexation occurs between rosuvastatin and selected ACE inhibitors at their carboxylic $(\mathrm{COOH})$ and hydroxyl $\mathrm{OH}$ sites.

The anti-nociceptive effect of complexes was assessed by formalin induced nociception in mice, antiinflammatory effect was evaluated by carrageenan induced paw edema in rats. Neuropharmacological behaviors were also studied on mice.

All the complexes of Rosuvastatin showed analgesic behavior in rats and mice. Anti-inflammatory activity of complexes is found insignificant. Enalapril complex keeps sedative activity while complexes with captopril and lisinopril contain anti-depressant behaviors.

Results suggest that the interaction of rosuvastatin with ACE inhibitors have consumed the active reacting sites of Rosuvastatin for which its anti-inflammatory, analgesic and gross locomotor behaviors have been affected. So it is suggested that Rosuvastatin should not be co-administered with any of these ACE inhibitors.
\end{abstract}

\section{Key words}

Hypercholesterolemia; Rosuvastatin; ACE inhibitors; Antiinflammatory; Analgesic; Neuropharmacology

\section{Abbreviations}

ROS: Rosuvastatin; RCC: Rosuvastatin-captopril-complex; REC: Rosuvastatin-enalapril-complex; RLC: Rosuvastatin-lisinopril-complex

\section{Introduction}

Rosuvastatin being a potent HMG CoA reductase inhibitor in controlling biosynthesis of hepatic cholesterol is used for the treatment of coronary artery disease [1], heart attacks, hyperlipidemia, hypercholesterolemia and hypertriglyceridemia. At contrary, continuous dosage of statins also causes myositis, rhabdomyolysis [2-4], atherosclerosis and liver transaminase elevation in patients with common symptoms of headache, gastrointestinal disorders, rash, diabetes, hypertension and nephrotic disease. Enalapril, Captopril and lisinopril belong to angiotensin-converting enzyme (ACE) inhibitors (Figure 1). They block the conversion of angiotensin I to angiotensin II in hypertension, collagen vascular and cardiovascular disease $[5,6]$, cardiac arrhythmias, myocardial infarction [7] and reduce the activity of blood pressure regulating rennin-angiotensin-converting enzyme in Barter's syndrome.

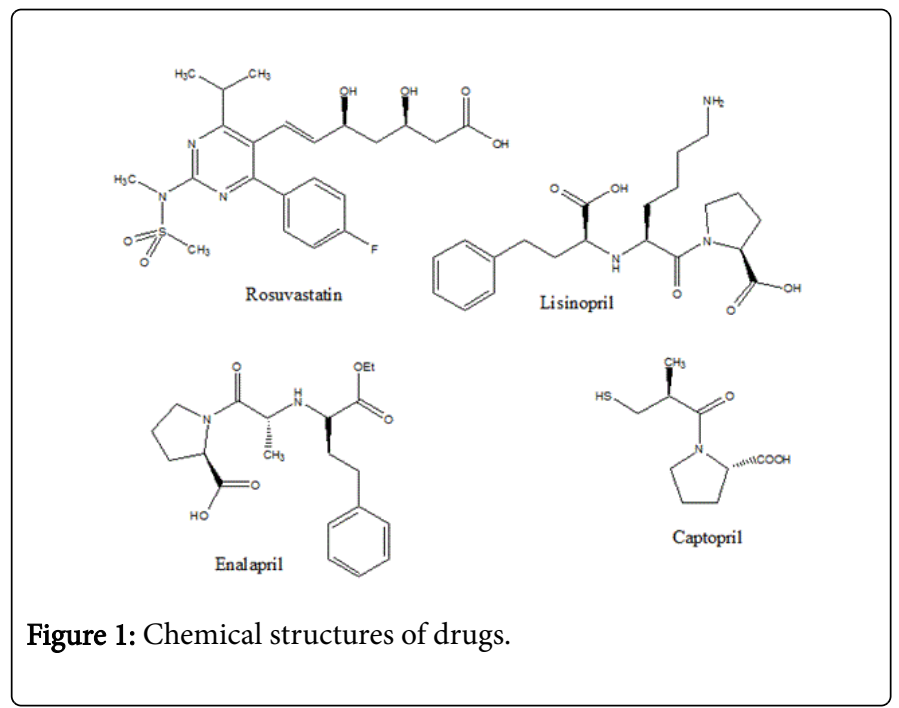

As clinical complexity of patients at high cardiovascular risk and with multiple comorbid conditions increases so does potential for drug-drug interactions (DDIs). Large surveying studies in various clinical fields have shown that large proportion of patients are coprescribed a statin with potentially interacting therapies, suggesting 
that the impact of polypharmacy on the safety profile of statins should be considered deeply.

Literature survey reveals a number of studies carried on derivatization of ROS [8-15], captopril [16-19], enalapril [20] and lisinopril $[21,22]$ but there is no study yet present on analogues of ROS and ACE inhibitors. Owing to the tendency of DDI of ROS due to the presence of number of electron donating sites, in vitro interactions were carried out it was reacted with anti-hypertensives and synthesis of complexes of ROS with enalapril, captopril and lisinopril are reported in this paper. Complexes were characterized with physical and spectroscopic techniques and potential in vivo pharmacological studies.

\section{Experimental}

\section{Materials and reagents}

Reference standards of ROS, enalapril, captopril and lisinopril were kind gifts from Pharm Evo Pvt. Ltd., Merck Sharp and Dome Ltd., BMS Pvt. Ltd. and Atco Laboratories Ltd. respectively. Analytical grade hydrochloric acid $(11 \mathrm{~N})$, HPLC grade methanol and acetonitrile were purchased from Merck, Darmstadt, Germany. Deionized doubly distilled water was used throughout. Pyrex A grade glasswares were used after washing with diluted chromic acid, water and deionized waters.

\section{Synthesis of compounds}

Rosuvastatin-enalapril-complex (REC), rosuvastatin-captoprilcomplex (RCC) and rosuvastatin-lisinopril-complex (RLC) were synthesized. ROS (1 mmole) and enalapril $(2 \mathrm{mmole})$ were separately dissolved in $40 \mathrm{~mL}$ methanol. Solutions were mixed in $100 \mathrm{~mL}$ round bottomed flask with constant stirring and refluxed for 3-4 hours at $70^{\circ} \mathrm{C}$ till the consumption of drugs. The progress of reaction was monitored by TLC. The volume of reaction mixture was reduced by rotary-evaporator. The precipitates were filtered and washed with chloroform at room temperature. The content was purified by recrystallization with methanol:chloroform (2:8) system. Crystals obtained were again checked by TLC and constant melting points (Table 1).

\begin{tabular}{|l|l|l|l|l|}
\hline Compounds & Color & State & $\begin{array}{l}\text { Melting } \\
\text { point }\end{array}$ & Solubility \\
\hline REC & Transparent & Crystalline & 110 & DMSO \\
\hline RCC & Brownish & Crystalline & 85 & DMF \\
\hline RLC & White & Crystalline & 70 & $\mathrm{MeOH}$ \\
\hline
\end{tabular}

Table 1: Physical characteristics of compounds.

\section{Instrumentation}

IR studies were carried out on Shimadzu Model FTIR Prestige-21 spectrophotometer using Shimadzu IR solution 1.2 software. 1H-NMR spectra were recorded on a Bruker AMX $300 \mathrm{MHz}$ spectrometer in $\mathrm{CD} 3 \mathrm{OD}$ and deutrated water with TMS as an internal standard.

\section{Pharmacological activities}

Animals: Male Swiss albino mice of 20-25 g and Wistar rats 200-225 $\mathrm{g}$ were used as test animals. They were housed in standard cages at room temperature under controlled light with free access to food and water. Animals submitted to oral administration of test samples were fasted for 12 hours.

Analgesic activity studies (Formalin test): Formalin solution $(20 \mu \mathrm{L}$; $2 \%)$ was injected in sub-plantar region of right hind paw of the mice to induce pain in the form of licking and biting responses. This test is done for the evaluation of antinociceptive effect. Aspirin as standard drug was administered orally 30 minutes before formalin injection to act as positive control while distilled water was given to serve as negative control. The test samples were administered orally (400 $\mathrm{mg} / \mathrm{kg}$ ) prior to the reaction. Licking and biting responses of the injected paw was considered as indicator of pain response $[23,24]$. The responses were counted in early phase for $5 \mathrm{~min}$ and for $30 \mathrm{~min}$ in late phase of formalin injection. Inhibition of pain or reduction in licking and biting responses was calculated by the following formula:

$\%$ inhibition $=($ mean of control group $)-($ mean of treated group $) /$ (mean of control group) $\times 100$

Anti-inflammatory activity studies: Studies were carried out after inducing inflammation in animals through carageenan injection [25]. Five groups of 6 rats each were taken. Test (or zero) group was treated intraperitoneal 30 minutes before carageenan injection. Group 1 was assigned positive control after receiving $300 \mathrm{mg} / \mathrm{kg}$ of aspirin; group 2 was made negative control after giving $0.1 \mathrm{~mL}$ distilled water $/ \mathrm{kg}$. Group 3 and 4 were given $400 \mathrm{mg}$ and $800 \mathrm{mg} / \mathrm{kg}$ of REC. Plethysmometer (Ugo Basile) was used to measure increase in paw diameter immediately and till four hours following carageenan injection. Difference in sizes of right and left hind paw indicates the extent of inflammation. The procedure was repeated for RCC and RLC and ROS with other groups of animals.

Neuropharmacological activity studies Gross behavioral activity: Method described by Irwin [26,27]was followed for gross behavioral activities. Shivering, licking/ biting, rashes, fits, irritation and urination were observed.

Locomotor and muscle relaxant activity: Methods described by Ahmad et al. [28] and Verma et al. [29]in their prior studies were followed for CNS activities of compounds. Cage cross, head dip, rearing, open field, traction test, light/dark and forced swim tests were performed by placing animals in specified chambers and observed their movements for 30 minutes.

Open field activity was carried out in a square box of $76 \times 76 \mathrm{~cm}$ and $42 \mathrm{~cm}$ high walls. The floor was divided into 25 equal squares. Mice were individually placed on the central square and number of squares crossed by each mouse with all four paws was counted for 15 minutes.

$1000 \mathrm{~mL}$ beaker lined with white paper at the bottom was taken for rearing test on control and treated mice. Mice were placed in the beaker individually and allowed to move upward with erect position of the body. Each erect position was counted for 30 minutes [30-32].

Square-shaped head-dip box having three holes on each side was designed. Mice were placed individually. Number of head dips from the holes was counted for 30 minutes [33-35].

Traction was performed in such a way that mice were allowed to move on an iron rod of $1 \mathrm{~m}$ in length. Mice were first trained to walk on the rod. Time taken to travel on the rod was noted [36-38]. 
In cage cross test mice were allowed to cross the cages individually to a specifically designed rectangular box. Their crossing movement was observed for 30 minutes [39-41].

In forced swim test (FST) mice were individually forced to swim in a glass tank of $56 \mathrm{~cm}$ height and $20 \mathrm{~cm}$ width with water contained to a height of $22 \mathrm{~cm}$ at $25^{\circ} \mathrm{C}$ for 6 minutes. The level of water in the tank was set so that mice neither touch the bottom of the tank nor jump out of it. Swimming behavior was noted and movement was counted.

Statistical analysis: Statistical data were expressed as mean \pm SEM [42]. Student's t-test values of $\mathrm{p}<0.05$ was applied for significance of difference between means.

\section{Results}

\section{Spectroscopic studies of synthesized compounds}

IR studies: In the IR spectrum of Rosuvastatin, a broad region of band was seen between $3625-3200 \mathrm{~cm}^{-1}$ that was indication of $\mathrm{OH}$ group. The presence of characteristic carbonyl stretched peak at 1654 $\mathrm{cm}^{-1}$ confirmed the $\mathrm{OH}$ peak was mainly of carboxylic group with overlapping hydroxyl group in the region of $3625-3200 \mathrm{~cm}^{-1}$. Adjacent to this band a sharp peak at $2926 \mathrm{~cm}^{-1}$ was seen which is specific for olefinic C-H of heptenoic side chain. Peak for bending vibrations of methyl C-H was present at $1453 \mathrm{~cm}^{-1}$ respectively. Peaks for distinguished sulfoxide group of the drug were confirmed by the presence of asymmetric and symmetric strong stretching vibrations at 1336 and $1155 \mathrm{~cm}^{-1}$ respectively. The C-F stretch of aromatic ring present in the compound was followed by the peak at $1230 \mathrm{~cm}^{-1}$ $[43,44]$.

The spectrum of lisinopril was observed with broad band of carboxylic $\mathrm{OH}$ between $3570-3510 \mathrm{~cm}^{-1}$. $\mathrm{sp}^{2}-\mathrm{CH}$ stretch was found at $3099 \mathrm{~cm}-1$. Carboxylic carbonyl stretching peak of at $1642 \mathrm{~cm}^{-1}$ and amide carbonyl stretch was present at $1575 \mathrm{~cm}^{-1}$. Primary amine asymmetric stretch was present at $1610 \mathrm{~cm}^{-1}$ and symmetric stretch of primary amine was found at $1506 \mathrm{~cm}^{-1} . \mathrm{C}=\mathrm{C}$ aromatic ring stretch was found at $1450 \mathrm{~cm}^{-1} .918-702 \mathrm{~cm}^{-1}$ was observed for $=\mathrm{C}-\mathrm{H}$ absorption [45].

In captopril, broad band of carboxylic $\mathrm{OH}$ was seen at 3543-3320 $\mathrm{cm}^{-1}$. Stretching peak of carboxylic carbonyl was present at 1747 $\mathrm{cm}^{-1}$ and amide carbonyl was observed at $1591 \mathrm{~cm}^{-1}$. SH stretch of Captopril was seen at $2565 \mathrm{~cm}^{-1}$ [46].

In the IR spectrum of enalapril it was found that $\mathrm{NH}$ stretch was present at $3200 \mathrm{~cm}^{-1}$. Peak for carboxylic $\mathrm{OH}$ was present at 3600-3300 $\mathrm{cm}^{-1}$ and carbonyl at $1725 \mathrm{~cm}^{-1}$. A peak at $1381 \mathrm{~cm}^{-1}$ was present for $\mathrm{C}-\mathrm{N}$ bond. Aromatic ring $\mathrm{C}=\mathrm{C}$ was observed at $1649 \mathrm{~cm}^{-1}$ [47].

In complex RLC, there is a band at $3525-3150 \mathrm{~cm}^{-1}$ for carboxylic $\mathrm{OH}$ of heptenoic acid site of ROS. In RCC is the band at 3460-3260 $\mathrm{cm}^{-1}$ that shows carboxylic $\mathrm{OH}$ and $1544 \mathrm{~cm}^{-1}$ for carbonyl peak. In REC, OH band is present at $3480-3100 \mathrm{~cm}^{-1}$ and carbonyl peak is present at $1562 \mathrm{~cm}^{-1}$.

${ }^{1} \mathrm{H}-\mathrm{NMR}$ studies: Characteristic ${ }^{1} \mathrm{H}-\mathrm{NMR}$ signals of ROS in $\mathrm{CDCl}_{3}$ at $300 \mathrm{MHz}$ showed a doublet at $1.23 \mathrm{ppm}$ for methyl hydrogen. Singlet proton at $1.40 \mathrm{ppm}$ for $\mathrm{CH}$ of heptenoic acid chain and another singlet was seen at 4.32-4.81 ppm for hydroxyl $\mathrm{OH}$. Singlet for protons of ethylene was observed at 6.25 and $6.65 \mathrm{ppm}$. Quartet of benzyl protons is present at 7.30-8.15 ppm. Proton of carboxylic acid was seen at 10.25 ppm as singlet [48].
The ${ }^{1} \mathrm{H}$-NMR signals of lisinopril in $\mathrm{CDCl}_{3}$ at $300 \mathrm{MHz}$ produced a singlet was present at $2.00 \mathrm{ppm}$ for primary and secondary amine. Singlet at 1.92 and $2.02 \mathrm{ppm}$ for $\mathrm{CH}_{2}$ protons of pyrollidone are observed. Quartet of benzyl protons was observed at 7.29-7.40 ppm. Singlet proton of carboxylic $\mathrm{OH}$ was present at $10.20 \mathrm{ppm}$.

The ${ }^{1} \mathrm{H}$-NMR spectrum for captopril in $\mathrm{CDCl}_{3}$ taken at $300 \mathrm{MHz}$ produced a singlet at $1.5 \mathrm{ppm}$ for mercapto proton. Methyl protons are seen in singlet at $1.19 \mathrm{ppm}$. Quartet for the protons of pyrollidine was observed at 2.02-2.33 ppm. Doublet for protons of methylene bonded with sulfur was present at $2.68-2.93 \mathrm{ppm}$. Another doublet for $\beta-\mathrm{CH}$ of pyrollidine was found at 3.41-3.51 ppm. Singlet proton at $10.20 \mathrm{ppm}$ was present for the presence of carboxylic hydroxyl proton.

In the ${ }^{1} \mathrm{H}$-NMR spectrum of enalapril, chemical shifts of amine proton as singlet at $2.00 \mathrm{ppm}$, pyrollidine protons as quartet at 4.33 ppm were observed. Phenyl protons were another quartet at 7.27-7.40 ppm. A singlet for the proton of carboxylic $\mathrm{OH}$ wa present at 9.50 ppm.

In RLC notable peak was present at $11.90 \mathrm{ppm}$ for carboxylic acid. In RCC peaks for carboxylic acid were present at $11.00 \mathrm{ppm}$, while in REC the same signal was present at $9.61 \mathrm{ppm}$.

\section{Pharmacological studies of synthesized complexes}

Analgesic activities: The licking and biting response of rats due to REC and RCC was $24 \pm 2.43$ and $24 \pm 1.76$ ( with $56.204 \%$ inhibition each), while RLC showed $31 \pm 2.46$ response with $43.431 \%$ inhibition against control $(54.8 \pm 4.45)$ and aspirin standard $(1.498 \pm 0.029$, $70.887 \%$ inhibition) in early phase of formalin injection.

In late phase of injection REC showed (17.6 $\pm 1.44,57.281 \%)$, RCC $(24 \pm 1.79,41.747 \%)$ and RLC $(20.6 \pm 0.75,50 \%)$ number of responses against control $(41.2 \pm 4.23)$ and Aspirin standard (1.21 \pm 0.04 , $86.854 \%)$ in licking and biting. \% inhibition to pain is calculated in Table 2 and Figure 2.

\begin{tabular}{|l|l|l|l|l|}
\hline \multicolumn{2}{|l|}{ phase 1 } & \multicolumn{2}{l|}{ phase 2 } \\
\hline Compounds & Licking/biting & $\begin{array}{l}\% \\
\text { inhibition }\end{array}$ & Licking/biting & $\begin{array}{l}\% \\
\text { inhibition }\end{array}$ \\
\hline Control & $54.8 \pm 4.45$ & -- & $41.2 \pm 4.23$ & - \\
\hline REC(400mg/kg) & $24 \pm 2.43$ & 56.204 & $17.6 \pm 1.44$ & 57.281 \\
\hline REC(800mg/kg) & $18.2 \pm 0.665$ & 66.788 & $15.954 \pm 0.546$ & 61.276 \\
\hline RCC & $24 \pm 1.76$ & 56.204 & $24 \pm 1.79$ & 41.747 \\
\hline RLC & $31 \pm 2.46$ & 43.431 & $20.6 \pm 0.75$ & 50 \\
\hline Aspirin & $1.498 \pm 0.029$ & 70.887 & $1.21 \pm 0.04$ & 86.854 \\
\hline ROS & $1.34 \pm 1.34$ & 97.554 & $1.564 \pm 0.43$ & 96.203 \\
\hline
\end{tabular}

Table 2: Formalin induced licking and biting response of compounds. 
Citation: Tabassum A, Arayne MS, Sultana N and Mehjabeen (2016) Synthetic Characterization of Complexes of Rosuvastatin and Some ACE Inhibitors: Pharmacological Evaluation. Pharm Anal Acta 7: 488. doi:10.4172/2153-2435.1000488

Page 4 of 8

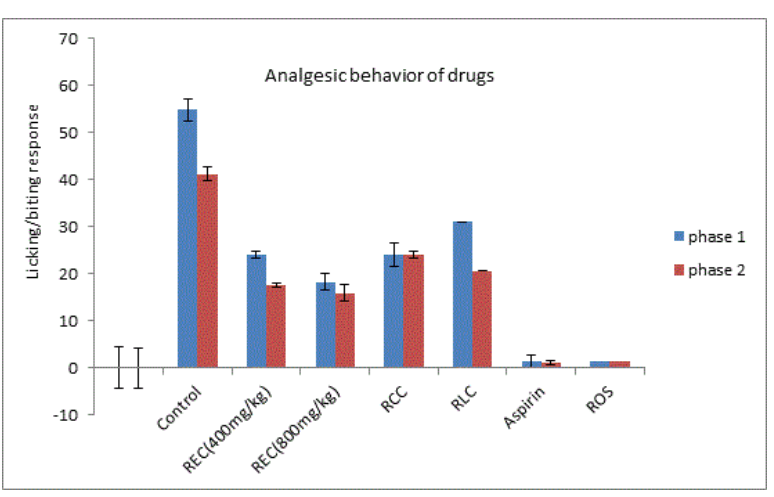

Figure 2: Graph showing analgesic effects of compounds.
Anti-inflammatory studies: Carageenan induced edema in animals showed negligible change in paw size in all cases of REC, RCC and RLC. The graph (Figure 3) shows very little anti- inflammatory response to edema when examined for four hours of drug injection. Difference of change in paw size is shown in Table 3.

CNS depressant activities Gross behavioral activities: After 30 minutes of drug administration $(400 \mathrm{mg} / \mathrm{kg}$ ), shivering in animals was found considerable with REC and RCC while it was lesser with RLC. Hyper sensitivity produced licking and biting in animals to high degree in all test compounds, RCC showed higher response.

Rashes were produced to a little extent with RCC and RLC and was very low in the presence of REC. Irritation was increased in all compounds. REC increased urination while RCC and RLC did not show such response. Fits were not produced by any compound.

\begin{tabular}{|l|l|l|l|l|l|}
\hline \multirow{2}{*}{ Compounds } & $\mathbf{0 ~ h r}$ & $\mathbf{1} \mathbf{~ h r}$ & $\mathbf{2} \mathbf{~ h r s}$ & $\mathbf{3 ~ h r s}$ & $\mathbf{4} \mathbf{h r s}$ \\
\cline { 2 - 6 } & $\mathbf{( m m}$ increase) & $\mathbf{( m m}$ increase) & (mm increase) & (mm increase) & (mm increase) \\
\hline Control & $1.418 \pm 0.0116$ & $1.302 \pm 0.0159$ & $1.27 \pm 0.0176$ & $1.176 \pm 0.02069$ & $1.186 \pm 0.01604$ \\
\hline REC(400mg/kg) & $1.478 \pm 0.025$ & $1.21 \pm 0.0406$ & $1.226 \pm 0.0232$ & $1.34 \pm 0.1203$ & $1.212 \pm 0.0097$ \\
\hline \% inhibition & 0.9383 & 13.5714 & 12.8023 & 5.0991 & 14.1643 \\
\hline REC(800mg/kg) & $1.444 \pm 0.0202$ & $1.266 \pm 0.0108$ & $1.158 \pm 0.0185$ & $1.14 \pm 0.0131$ & $1.212 \pm 0.009$ \\
\hline \% inhibition & 6.8387 & 4.0909 & 17.8723 & 17.9856 & 12.8057 \\
\hline RCC & $1.502 \pm 0.017$ & $1.404 \pm 0.011$ & $1.438 \pm 0.022$ & $1.442 \pm 0.015$ & $1.47 \pm 0.018$ \\
\hline \% inhibition & 5.9238 & 7.8341 & 13.2283 & 22.619 & 23.946 \\
\hline RLC & $1.48 \pm 0.015$ & $1.43 \pm 0.016$ & $1.394 \pm 0.011$ & $1.386 \pm 0.007$ & $1.388 \pm 0.0037$ \\
\hline \% inhibition & 4.3723 & 9.831 & 9.7638 & 17.8571 & 17.032 \\
\hline Aspirin & $1.98 \pm 0.0293$ & $1.21 \pm 0.0406$ & $1.226 \pm 0.0232$ & $1.34 \pm 0.1203$ & $1.212 \pm 0.0097$ \\
\hline \% inhibition & 8.333 & 13.05 & 3.597 & 12.806 & 32.708 \\
\hline ROS & $1.1 \pm 0.01$ & $1.00 \pm 0.02$ & $0.94 \pm 0.03$ & $0.56 \pm 0.03$ & $0.47 \pm 0.03$ \\
\hline \% inhibition & 22.42 & 23.19 & 25.98 & 52.38 & 60.37 \\
\hline
\end{tabular}

Table 3: Anti-inflammatory activity of compounds.

$800 \mathrm{mg} / \mathrm{kg}$ dose of REC given to animals showed elevated response. Shivering, licking and biting and urination were very high while irritation was highest, however fits and rashes were not observed (Table 4).

Locomotor and muscle relaxant activities: Locomotor responses in the presence of these three test compounds were observed and compared with those of diazepam and ROS. Animals were allowed to cross the cage after 30 minutes of administration of compounds. REC took $6.6 \pm 1.367$ minutes, RCC took $18.4 \pm 0.814$ minutes and RLC took $20.8 \pm 1.74$ minutes to come out of the cage while diazepam standard and control took $7 \pm 0.07$ and $28 \pm 1.143$ minutes respectively.

Head dip response of animals during 30 minutes after administration of compounds: as compared to diazepam $(6 \pm 0.06$ min) was $5.1 \pm 1.725$ minutes with REC, $15.2 \pm 3.82$ minutes with RCC, $22.8 \pm 1.72$ minutes with RLC and $27.6 \pm 0.929$ minutes with control $(27.6 \pm 0.929 \mathrm{~min})$.

Rearing response as compared to diazepam ( $4 \pm 0.03$ minutes) was 4 \pm 0.03 minutes for control, $9.2 \pm 1.659$ minutes for REC, $19.4 \pm 0.93$ minutes for RCC and 21.6 \pm 1.69 minutes for RLC.

Open field response of mice to assess the fearfulness and emotional reactivity of mice was observed for 30 minutes during which diazepam showed $26 \pm 0.09$ counts, control showed $232.2 \pm 6.321$, REC (131.8 \pm 14.877), RCC (142.6 \pm 3.49$)$ and RLC (158 \pm 2.99$)$ counts. 
Citation: Tabassum A, Arayne MS, Sultana N and Mehjabeen (2016) Synthetic Characterization of Complexes of Rosuvastatin and Some ACE Inhibitors: Pharmacological Evaluation. Pharm Anal Acta 7: 488. doi:10.4172/2153-2435.1000488

Page 5 of 8

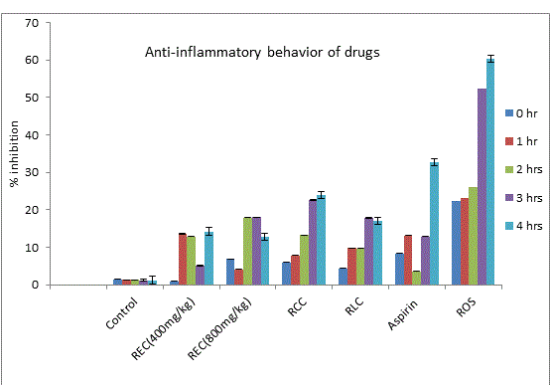

Figure 3: Graph showing anti-inflammatory effects of compounds.

\begin{tabular}{|l|l|l|l|l|l|l|}
\hline Compounds & $\begin{array}{l}\text { Shiverin } \\
\mathbf{g}\end{array}$ & $\begin{array}{l}\text { Licking/ } \\
\text { biting }\end{array}$ & $\begin{array}{l}\text { Rashe } \\
\mathbf{s}\end{array}$ & Fits & Urine & Irritation \\
\hline $\begin{array}{l}\text { REC } \\
(400 \mathrm{mg} / \mathrm{kg})\end{array}$ & $2+$ & $2+$ & $2-$ & $3-$ & $2+$ & $2+$ \\
\hline $\begin{array}{l}\text { REC } \\
(800 \mathrm{mg} / \mathrm{kg})\end{array}$ & $3+$ & $6+$ & $4-$ & $4-$ & $3+$ & $9+$ \\
\hline RCC & $1+$ & $3+$ & $1+$ & $1-$ & $1-$ & $2+$ \\
\hline RLC & $2-$ & $2+$ & $1+$ & $1-$ & $1-$ & $2+$ \\
\hline
\end{tabular}

Table 4: Gross behavioral activities of compounds.

In traction test carried out for muscle relaxant activity of mice, diazepam administered animals fell within $0.6 \pm 0.02$ seconds while control took $7.4 \pm 1.252 \mathrm{sec}$, REC $(31.4 \pm 2.16)$, RCC $(33.426 \pm 1.74)$ and RLC $(1.37 \pm 0.08)$ seconds. After subjecting them for light dark activity test, mice were in dark for $6.44 \pm 0.15$ minutes with REC, 6.818 \pm 0.14 minutes with RCC and $7.102 \pm 0.145$ minutes with RLC while diazepam dosed mice took $8.01 \pm 1.03$ minutes. The control had $6.91 \pm$ 0.26 minutes in dark.

Mobility time of animals in FST was noted by placing them in a tank filled with water explained as above and observing their movement from one end to other. Animals with REC took $1.78 \pm 0.12$ minutes, RCC took $1.25 \pm 0.025$ minutes, RLC took $1.338 \pm 0.05$ minutes against control (4.124 \pm 0.037 minutes) and diazepam (1.044 \pm 0.02 ) minutes. (Figures $4 \mathrm{a}-\mathrm{d}$ )

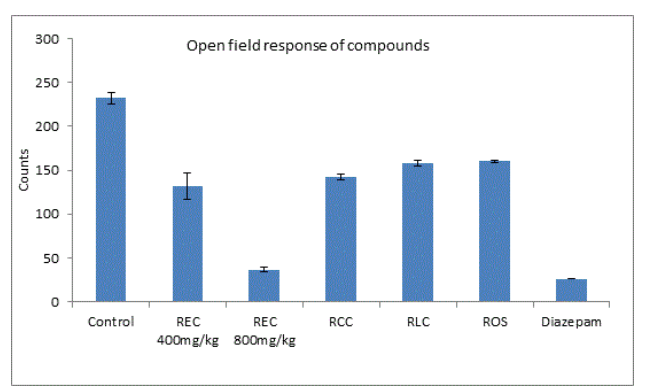

Figure 4a : Graph showing open field response of compounds during neuropharmalogical studies.

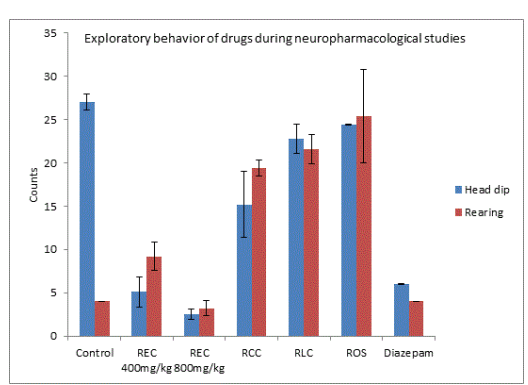

Figure 4b: Graph showing neuropharmalogical effects of compounds.

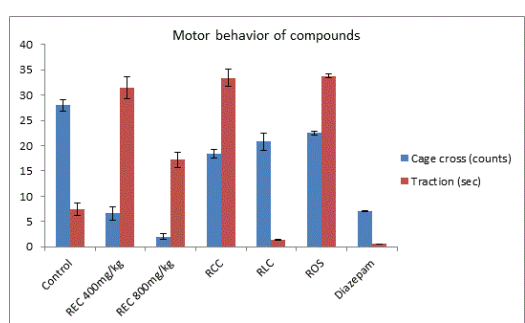

Figure $4 c$ : Graph showing motor behavior of compounds during neuropharmalogical studies.

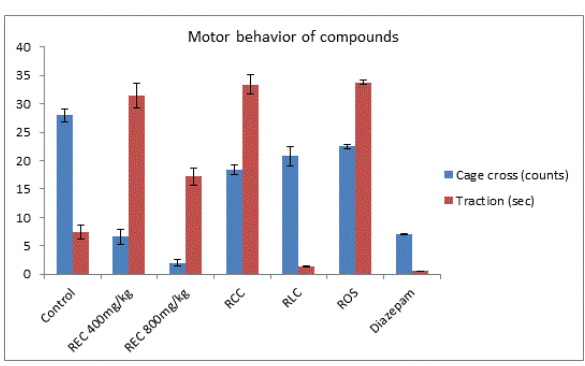

Figure 4d : Graph showing motor behavior of compounds during neuropharmalogical studies.

\section{Discussion}

Complexes of rosuvastatin with ACE inhibitors were subjected to characterization by IR and $1 \mathrm{H}-\mathrm{NMR}$ spectroscopic studies so that nature of bond can be elucidated.

\section{Spectroscopic studies of synthesized complexes}

IR studies: The IR spectral analysis of RLC provided that the major changes as the absorption frequencies of carbonyl of both ROS and lisinopril were shifted towards right. The band for $\mathrm{OH}$ of heptenoic acid site also shifted to lower frequencies $3525-3150 \mathrm{~cm}^{-1}$. This indicates the participation of $\mathrm{OH}$ and carbonyl bonds of both molecules (Figure 5a).

Similar trend in shifting of carbonyl and $\mathrm{OH}$ bands towards lower frequency was seen in complexes RCC and REC. In RCC, the OH was 
Citation: Tabassum A, Arayne MS, Sultana N and Mehjabeen (2016) Synthetic Characterization of Complexes of Rosuvastatin and Some ACE Inhibitors: Pharmacological Evaluation. Pharm Anal Acta 7: 488. doi:10.4172/2153-2435.1000488

Page 6 of 8

observed at $3460-3260 \mathrm{~cm}^{-1}$ and carbonyl stretch was shifted to 1544 $\mathrm{cm}^{-1}$. In REC, OH shift was found at $3480-3100 \mathrm{~cm}^{-1}$ with carbonyl peak at $1562 \mathrm{~cm}^{-1}$. (Figure $5 \mathrm{~b}$ and $5 \mathrm{c}$ )

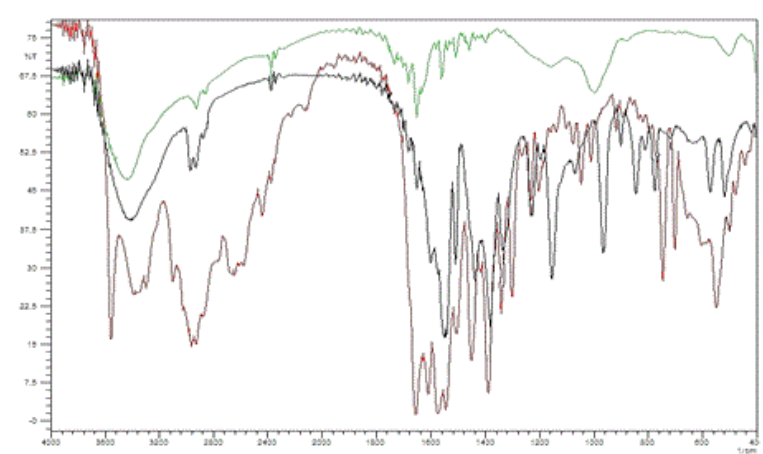

Figure 5a: Representative IR spectra of rosuvastatin (black), lisinopril (red) and their complex (green).

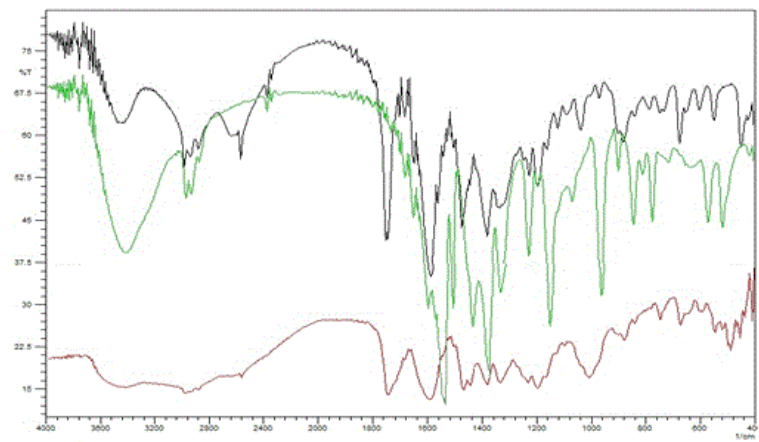

Figure 5b: Representative IR spectra of rosuvastatin (green), captopril (black) and their complex (red).

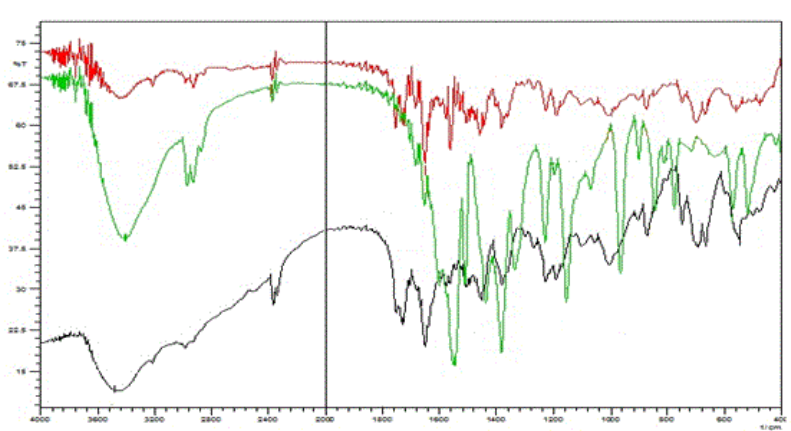

Figure 5c: Representative IR spectra of rosuvastatin (green), enalapril (red) and their complex (black).

The comparison of IR spectra of ROS with its complexes showed that the changes were occurred at the $\mathrm{OH}$ site of carboxyl of each interacting compounds while rest of the peaks had undisturbed shifts (Table 2). The changes show the involvement of these sites in complexation.
1H-NMR studies: The results of proton NMR analyses of these compounds are in accordance with the results of IR studies.

On comparing the spectrum of RLC with ROS and lisinopril the signals of carboxylic acid protons there was deshielding effect due to presence of hydrogen bonding between carboxylic acid site of lisinopril and heptenoic acid site of ROS.

Downfield shift in heptenoic acid OH of ROS was from 10.25 to $11.00 \mathrm{ppm}$ and 10.20 from $10.50 \mathrm{ppm}$ in captopril. In the complex with enalapril, there was downfield shift seen at $10.58 \mathrm{ppm}$ for ROS and $9.61 \mathrm{ppm}$ for the carboxylic of enalapril [48].

There is downfield shift in carboxylic and hydroxyl OH of ROS with indifferent changes in other signals. In lisinopril, captopril and enalapril the signals of carboxylic $\mathrm{OH}$ have been shifted down field. Characteristic IR and NMR signals have been demonstrated in Table 2.

The spectral studies show that the new compounds have been formed by multiple hydrogen bonding between $\mathrm{OH}$ (carboxylic and hydroxyl) of $\mathrm{ROS}$ and $\mathrm{OH}$ (carboxylic) of interacting compounds lisinopril, captopril and enalapril because no bond breaking seen. The complexes possess distinguished physical characteristics also (Table 1 and 5).

\begin{tabular}{|l|l|l|l|l|}
\hline & \multicolumn{2}{|l|}{ phase 1 } & \multicolumn{2}{l|}{ phase 2 } \\
\hline Compounds & Licking/biting & $\begin{array}{l}\% \\
\text { inhibition }\end{array}$ & Licking/biting & $\begin{array}{l}\% \\
\text { inhibition }\end{array}$ \\
\hline Control & $54.8 \pm 4.45$ & -- & $41.2 \pm 4.23$ & -- \\
\hline REC(400mg/kg) & $24 \pm 2.43$ & 56.204 & $17.6 \pm 1.44$ & 57.281 \\
\hline REC(800mg/kg) & $18.2 \pm 0.665$ & 66.788 & $15.954 \pm 0.546$ & 61.276 \\
\hline RCC & $24 \pm 1.76$ & 56.204 & $24 \pm 1.79$ & 41.747 \\
\hline RLC & $31 \pm 2.46$ & 43.431 & $20.6 \pm 0.75$ & 50 \\
\hline Aspirin & $1.498 \pm 0.029$ & 70.887 & $1.21 \pm 0.04$ & 86.854 \\
\hline ROS & $1.34 \pm 1.34$ & 97.554 & $1.564 \pm 0.43$ & 96.203 \\
\hline
\end{tabular}

Table 5: Formalin induced licking and biting response of compounds.

\section{Pharmacological studies of complexes}

Analgesic activity studies: Results of formalin test indicated that all compounds (REC, RCC, RLC) showed significant response to licking and biting produced by formalin injection in both phases than standard drug (aspirin used). They exhibited high rate of inhibition (57.281, 41.747 and $50 \%$ respectively) but it is less than that of standard (70.887 and 86.854\%). Compared from studies carried out by Ghaisas and coworkers [49] rate of inhibition of ROS is high and is greater than that of standard. This shows that the compounds are less effective than standard and their parent drug; however they have potent analgesic effect to pain. (Table 3 and Figure 3)

Anti-inflammatory activities: The anti-inflammatory effects of compounds were studied using carageenan induced edema model. From statistical correlation of our studies, REC, RCC and RLC showed less inhibition to inflammation than aspirin standard (Table 4 and Figure 4).

Further REC was examined in two dosages $(400 \mathrm{mg} / \mathrm{kg}$ and $800 \mathrm{mg} /$ $\mathrm{kg}$ ). Both doses did not show distinguished inhibition to pain. Rate of 
inhibition of ROS (60\%) was in correspondence with the work done by Ghaisas and coworkers [49]. The graph shows that all three test compounds show lesser anti-inflammatory response to edema than their parent drug i.e, ROS having potent anti-inflammatory response. Percent inhibition observed for four hours of drug injection is shown in Table 4. Figure 4 shows significance of inhibition of compounds.

\section{CNS depressant activity studies}

Gross behavioral activities: Table 4 shows that all three compounds with $400 \mathrm{mg} / \mathrm{kg}$ dose exhibited hypersensitivity in mice and less shivering with RLC. Fits were absent in all. $800 \mathrm{mg} / \mathrm{kg}$ dose of REC had all the parameters with prominent high response making it toxic. Diuresis was found with REC in both doses. (Table 5)

Effect on locomotor activities: Locomotor and muscle relaxant activities of mice were observed by cage cross, head dip, rearing, open field, traction test and mobility by FST.

Open field activity of mice is done for their general locomotor behavior and anxiety level $[50,51]$. In experiments at $400 \mathrm{mg} / \mathrm{kg}$ dose of all test drugs, open field response of mice is shown from lowest to highest degree: Diazepam $>$ REC $>$ RCC $>$ RLC $>$ Control (Figure 5a). Similar increasing trend was observed in head dip activity i.e., REC $>$ diazepam > RCC > RLC and control. Rearing response of RCC and RLC-treated mice were very high while REC showed low activity. Results with REC were like those of standard and control. These results showed high exploratory behavior with RCC and RLC like ROS while low with REC (Figure 5b).

Locomotor activity of mice shows sedative or stimulating effect of drug. In cage cross activity REC took less time to come out of cages unlike diazepam while RCC and RLC showed ease and took longer time to cross the cages and their results were like controlled and parent-drug treated mice. Traction test showed that all three test-drugs had muscle relaxing response as they all withstood longer however they all fell down at last. Results were similar to those of ROS. Diazepam-dosed mice could not move more than $0.6 \pm 0.2 \mathrm{sec}$ (Figure 5c).

During light/dark activity mice showed moderate movement in light. They all behaved like controlled and standard mice. Their response was similar to ROS also. In forced swim test, test-drug dosed mice behaved like those of diazepam and ROS. Increased immobility shows less struggle and all these compounds have response similar to their parent ROS (Figure 5d).

When $400 \mathrm{mg} / \mathrm{kg}$ REC with dose was compared with new dose of $800 \mathrm{mg} / \mathrm{kg}$, the effect on all these activities was quite near the results of diazepam with increased irritation and diuresis.

Overall REC at both doses (400 and $800 \mathrm{mg} / \mathrm{kg}$ ) showed it sedative like diazepam however high dose induced irritation also. RCC and RLC showed them as anti-depressant and results were like rosuvastatin.

\section{Conclusion}

Interacting products i.e., REC, RCC and RLC were synthesized. Interaction between drugs had suffered the drugs from formation of hydrogen-bonded complexes that have consumed the active sites of drugs. Newly formed complexes also have analgesic response but less than that of rosuvastatin. They all show less anti-inflammatory character unlike ROS. RCC and RLC can act as anti-depressant while
REC as sedative. Results also conclude that the complexation of parent drugs when co-administered can also reduce their efficacy reducing their availabilities inside body. Hence it is suggested that administration of rosuvastatin with any of enalapril, captopril or lisinopril should be avoided.

\section{References}

1. Niddam-Hildesheim V, Sterimbaum G (2008) Teva Pharmaceutical Industries Ltd. Process for preparation of rosuvastatin calcium.

2. Bellosta S, Paoletti R, Corsini A (2004) Safety of statins: focus on clinical pharmacokinetics and drug interactions. Circulation 109: III50-57.

3. Omar MA, Wilson JP (2002) FDA adverse event reports on statinassociated rhabdomyolysis. Ann Pharmacother 36: 288-295.

4. Staffa JA, Chang J, Green L (2002) Cerivastatin and reports of fatal rhabdomyolysis. N Engl J Med 346: 539-540.

5. Burris JF (1995) The expanding role of angiotensin converting enzyme inhibitors in the management of hypertension. J Clin Pharmacol 35: 337-342.

6. Chobanian AV, Bakris GL, Black HR, Cushman WC, Green LA (2003) Seventh Report of the Joint National Committee on prevention, detection and evaluation, and treatment of high blood pressure. Hypertension 42: 1206-1252.

7. Murdoch DR, McMurray JJ (1998) ACE inhibitors in acute myocardial infarction. Hosp Med 59: 111-115.

8. Chapman MJ (2007) From pathophysiology to targeted therapy for atherothrombosis: a role for the combination of statin and aspirin in secondary prevention. Pharmacol Ther 113: 184-196.

9. Taylor AJ, Bindeman J, Feuerstein I, Le T, Bauer K (2008) Communitybased provision of statin and aspirin after the detection of coronary artery calcium within a community-based screening cohort. J Am Coll Cardiol 51: 1337-1341.

10. López-Canales JS, López-Sanchez P, Perez-Alvarez VM, Wens-Flores I, Polanco AC (2011) The methyl ester of rosuvastatin elicited an endothelium-independent and 3-hydroxy-3- methylglutaryl coenzyme A reductase-independent relaxant effect in rat aorta. Braz J Med Biol Res 44: 438-444.

11. Hirai K, Ishiba T, Koike H, Watanabe M (2000) Shionogi Seiyaku Kabushiki Kaisha, Pyrimidine derivatives as HMG-Co A reductase inhibitors.

12. Aronhime J, Hildesheim VN (2005) Crystalline ammonium salts of rosuvastatin. Teva Pharmaceutical Industries Ltd, assignee.

13. De Shantanu, Kumar Y, Rafeeq M, Sathyanarayana S (2005) Salts of HMG Co A reductase inhibitors and use thereof.

14. Lindsay D, Jackson P, Hindley S, Bhamra I (2011) Rosuvastatin and atorvastatin derivatives. Bredford Pharma limited.

15. Hildesheim VN, Shenkar N, Wizel S (2011) Crystalline rosuvastatin intermediate. Teva Pharmaceutical industries limited .

16. Tehrani MHH, Zarghi A, Jabarian LE (2005) Design and synthesis of new imidazole derivatives of captopril. IJPR 4: 37-41.

17. 17, Moss GP, Gullick DR, Cox PA, Alexander C, Ingram MJ, et al. (2006) Design, synthesis and characterization of captopril prodrugs for enhanced percutaneous absorption. J Pharm Pharmacol 58: 167-177.

18. Li HP, Zhang JJ, Qin L, Zhao MD (2013) Synthesis and characterization of captopril derivatives. Res CHEM Intermed 39: 621-629.

19. Al-Masoudi NA, Hamad NS, Hameed S, Pannecouque C (2010) Amino acid derivatives. Part 6 . New analogs of the angiotensin converting enzyme 'Captopril'. Synthesis and anti-HIV activity. Archive for Organic Chemistry 242-253.

20. Iwanaga Y, Gu Y, Dieterle T, Presotto C, Del Soldato P (2004) A nitric oxide-releasing derivative of enalapril, NCX 899, prevents progressive cardiac dysfunction and remodeling in hamsters with heart failure. FASEB J 18: 587-588.

21. Femia FJ, Maresca KP, Hillier SM, Zimmerman CN, Joyal JL (2008) Synthesis and evaluation of a series of $99 \mathrm{mtc}$ (co) $3+$ lisinopril 
Citation: Tabassum A, Arayne MS, Sultana N and Mehjabeen (2016) Synthetic Characterization of Complexes of Rosuvastatin and Some ACE Inhibitors: Pharmacological Evaluation. Pharm Anal Acta 7: 488. doi:10.4172/2153-2435.1000488

Page 8 of 8

complexes for in vivo imaging of angiotensin-converting enzyme expression. J Nucl Med 49: 970-977.

22. Watermeyer JM, Kröger WL, O'Neill HG, Sewell BT, Sturrock ED (2010) Characterization of domain-selective inhibitor binding in angiotensinconverting enzyme using a novel derivative of lisinopril. Biochem J 428 67-74.

23. de Miranda FG, Vilar JC, Alves IA, Cavalcanti SC, Antoniolli AR (2001) Antinociceptive and antiedematogenic properties and acute toxicity of Tabebuia avellanedae Lor. ex Griseb. inner bark aqueous extract. BMC Pharmacol 1: 6 .

24. Hunskaar S, Hole K (1987) The formalin test in mice: dissociation between inflammatory and non-inflammatory pain. Pain 30: 103-114.

25. winter CA, Risley EA, Nuss GW (1962) Carrageenin-induced edema in hind paw of the rat as an assay for antiiflammatory drugs. Proc Soc Exp Biol Med 111: 544-547.

26. Irwin S (1964) Drug screening and evaluation of new compounds in animals. In: Animals and clinical pharmacologic techniques in drug evaluation. Chicago: Year Book Medical Publishers, 36-54.

27. Hussain J, Ur Rehman N, Hussain H, Al-Harrasi A, Ali L, et al. (2012) Analgesic, anti-inflammatory, and CNS depressant activities of new constituents of Nepeta clarkei. Fitoterapia 83: 593-598.

28. Ahmad M, Mehjabeen, Zia UH, Jahan N (2011) Determination of LD50 and ED50 by dose response relationship and assessment of toxicological and non toxicologicalbehaviour of Ipomoea hederacea. J Pharm Res 4: 1176-1178.

29. Verma A, Jana GKR, Sen S, Chakraborty R, Achan SS, et al. (2010) Pharmacological evaluation of Saraca indica leaves for central nervous system depressant activity in mice. J Pharm Sci Res 2: 338-343.

30. Wyttenbach A, Furrer V, Schleppi P, Tobler L (1998) Rare earth elements in soil and in soil-grown plants. Plant and Soil 199: 267-273.

31. Yadav AV, Kawale LA, Nade VS (2008) Effect of Morus alba L. (mulberry) leaves on anxiety in mice. Indian J Pharmacol 40: 32-36.

32. Zia-Ul-Haq M, Cavar S, Qayum M, Khan I, Ahmad S (2013) Compositional studies and antioxidant potential of Acacia leucophloea Roxb. Acta Bot Croatica 72: 133-144.

33. Kennett GA, Dickinson SL, Curzon G (1985) Central serotonergic responses and behavioural adaptation to repeated immobilisation: the effect of the corticosterone synthesis inhibitor metyrapone. Eur J Pharmacol 119: 143-152.

34. Kennett GA, Dickinson SL, Curzon G (1985) Enhancement of some 5HT-dependent behavioural responses following repeated immobilization in rats. Brain Res 330: 253-263.

35. Turner RA, Hebborn P (1965) Screening Methods in Pharmacology. New York, NY, USA: Academic Press.

36. Sánchez-Mateo CC, Prado B, Rabanal RM (2002) Antidepressant effects of the methanol extract of several Hypericum species from the Canary Islands. J Ethnopharmacol 79: 119-127.
37. Kasture VS, Deshmukh VK, Chopde CT (2002) Anxiolytic and anticonvulsive activity of Sesbania grandiflora leaves in experimental animals. Phytother Res 16: 455-460.

38. Chattopadhyay D, Arunachalam G, Mandal SC, Bhadra R, Mandal AB (2003) CNS activity of the methanol extract of Mallotus peltatus (Geist) Muell Arg. leaf: an ethnomedicine of Onge. J Ethnopharmacol 85: 99-105.

39. Riaz M, Zia-Ul-Haq M, Ur-Rahman N, Ahmadi M (2014) Neuropharmacological effects of methanolic extracts of Rubusfruticosus L. Turk J Med Sci 44: 454-460.

40. Crestani F, Martin JR, Möhler H, Rudolph U (2000) Mechanism of action of the hypnotic zolpidem in vivo. Br J Pharmacol 131: 1251-1254.

41. Sakina MR, Dandiya PC (1990) A psychopharmacological profile of Centella asiatica extract. Fitoterapia 61: 291-296.

42. Alcaraz MJ, Jimenez MJ, Valverde S, Sanz J, Rabanal RM, et al. (1989) Anti-inflammatory compounds from Sideritis javalambrensis n-hexane extract. J Nat Prod 52: 1088-1091.

43. Badawy AM, El-Alim Ael-A, Saad AS (2011) Stability indicating spectrophotometric methods for determination of rosuvastatin in the presence of its acid degradation products by derivative spectrophotometric techniques. Drug Test Anal 2: 44-55.

44. Akbari BV, Valaki BP, Maradiya VH, Akbari AK, Vidyasagar G (2011) Optimization of super disintegrants and subliming agent on dissolution rate of rosuvastatin orodispersible tablets by using a 32 factorial design. Pharmacieglobale international journal of comprehensive pharmacy 2: 1-7.

45. Ferreira SH (1965) A Bradykinin-Potentiating Factor (Bpf) Present in the Venom of Bothrops Jararca. Br J Pharmacol Chemother 24: 163-169.

46. Bernstein KE, Martin BM, Edwards AS, Bernstein EA (1989) Mouse angiotensin-converting enzyme is a protein composed of two homologous domains. J Biol Chem 264: 11945-11951.

47. Soubrier F, Alhenc-Gelas F, Hubert C, Allegrini J, John M, et al. (1988) Two putative active centers in human angiotensin I-converting enzyme revealed by molecular cloning. Proc Natl Acad Sci U S A 85: 9386-9390.

48. Arayne MS, Sultana N, Tabassum A (2014) In Vitro Interaction Studies of Rosuvastatinand ACE-inhibitors by HPLC, Open Journal of Biochemistry 1: 34-44.

49. Ghaisas MM, Dandawate PR, Zawar SA, Ahire YS, Gandhi SP (2010) Antioxidant, antinociceptive and anti-inflammatory activities of atorvastatin and rosuvastatin in various experimental models. Inflammopharmacol 18: 169-177.

50. Hossain MS (2013) Analgesic and Neuropharmacological activity of methanolic extract of Calamus tenuis Roxb. Fruits. Journal of Scientific and Innovative Research 2: 1067-1072.

51. Boissy A (1998) Fear and fearfulness in animals. Q Rev Biol 70: 165-191. 